\title{
Analysis of Problems Posed by Pre-service Primary Teachers about Adding Fractions in terms of Semantic Structures
}

\author{
Tuğrul Kar1, and Cemalettin Iş1k², \\ ${ }^{1}$ Department of Primary Mathematics Education, K.K. Faculty of Education, Atatürk \\ University, Erzurum, Turkey \\ 2 Department of Primary Mathematics Education, Faculty of Education, Erciyes University, Kayseri, \\ Turkey
}

\begin{abstract}
This study aims to analyze problems posed by pre-service primary teachers about addition operations with fractions according to semantic structures. In addition, the study also investigated the means in which errors varied according to the semantic structures of the problems. Pre-service teachers were administered a problem posing test of four items of an addition operation with fractions. They were assigned to pose two different problems for each item related to daily situations that could only be solved with the given operations. First, problems posed were classified in the form of part-part-whole and join problems according to their semantic structures. Next, problems were analyzed according to the types of errors they involved. It was revealed that pre-service teachers generally preferred part-part-whole type of problems. Eight types of errors were determined in the problems posed. Moreover, it was identified that pre-service teachers, who used both structures as part-part-whole and join types in problems they posed, made less errors.
\end{abstract}

Keywords: Problem Posing, Addition Operation with Fractions, Pre-Service Primary Teachers, Word Problems

\section{INTRODUCTION}

Problem posing has achieved an increased level of interest among research studies on mathematics education in recent years. At the center of this interest lies the contribution of problem posing to students and teachers. Problem posing improves students' reasoning, problem solving, communication, and creativity skills (Abu-Elwan, 2002; Barlow \& Cates, 2006; Cai \& Hwang, 2002; Dickerson, 1999; English, 1998; Silver, 1994; Toluk-Ucar, 2009; Yuan \& Sriraman, 2010). Besides, problem posing enables teachers to comprehend students' skills, attitudes and conceptual learning within a given situation (Lavy \& Shriki, 2007). Stoyanova (1998) emphasized a strong agreement among researchers that problems posed by students provided clues about their mathematical skills.

Problem posing involves the generation of new problems and questions in order to explore a given situation as well as the reformulation of a problem during the course of solving it (Silver, 1994). According to the National Council of Teachers of Mathematics [NCTM] (2000), it involves the formulation of a new problem based on a given situation or 
experience. Generally, problem posing is defined as the generation of new problems and reformulating an existing problem (Cai \& Hwang, 2002; English, 2003). The literature presents various frameworks on problem posing activities (Christou et al., 2005; Contreras, 2007; Stoyanova \& Ellerton, 1996). Additionally, the framework proposed by Stoyanova and Ellerton (1996) in the form of free situations, structured situations and semi-structured situations, is the most common usage.

- In free problem posing, students are not given any problems. They are expected to pose problems appropriate to the given natural situation without any limitations (i.e. pose a problem about money).

- In semi-structured problem posing, students are given an open-ended situation. Students are expected to complete the open-ended situation in the form of a problem using their knowledge, skills, and experiences. Posing problems based on pictures, equations, and open-ended verbal stories are examples of semi-structured situations (i.e. pose a problem that could be solved with the following operation: $\frac{1}{2}+\frac{3}{4}=$ ? ).

- In structured problem posing teachers develop special problem solving strategies and ask students to pose problems that require the use of these strategies in solving problems.

Studies from the last decade indicate that pre-service teachers have difficulties posing problems on operations with fractions (Işık, 2011; Iş1k \& Kar, 2012; Işık et al., 2013; Kılıç, 2013; Luo, 2009; McAllister \& Beaver, 2012; Ticha \& Hospesova, 2009; Toluk-Uçar, 2009). The aforementioned researchers asked pre-service teachers to pose problems that could be solved using the $\frac{1}{4} \times \frac{2}{3}$ operation. The researchers found that pre-service teachers avoided the conceptual dimension of the given operation, failed to relate it to real life situations, and posed problems using the addition operation instead of multiplication. Issik (2011) emphasized that pre-service teachers had difficulties with the conceptual dimension of the fractions and fraction operations and that problem posing allowed pre-service teachers to develop a deep understanding about the difficulties they faced about fraction operations. Toluk-Ucar (2009) identified that pre-service primary teachers posed problems on addition of natural numbers instead of addition operation with fractions and they considered fractions as the number of pieces instead of the amounts. Issik et al. (2013) investigated the skills of primary school pre-service teachers to determine the errors in problems of addition operation with fractions posed by fifth grade students. It was concluded that teachers had more difficulties in determining errors in expressing fraction numbers with appropriate units, relating the amount indicated by fractions to the referenced whole, and establishing the relationship between the part and the whole. K1lıç (2013) investigated the types of meanings implied by fractions, which were prioritized by pre-service primary teachers in problems they posed on fraction operations. It was found that problems posed on dividing and subtracting fractions were less in number and that the operational meaning of fractions was prioritized. McAllister and Beaver (2012) expressed the prominence of errors in problems on fractions posed by pre-service primary teachers in the form of not being able to pose problems with daily life situations, not being able to write fraction numbers in accurate units, posing illogical problems, and attributing the natural number meaning to fractions.

The education system in Turkey consists of five hierarchical parts, including: kindergarten, primary school (Grades 1-4), middle school (Grades 5-8), high school (Grades 9-12), and university. In the mathematics curriculum structured for these levels, problem posing is defined as the final stage of the problem solving process. Fractions are begun to be taught in the second grade and it continues until the end of sixth grade. During this process, programs emphasize posing and solving problems related to daily life, which would require operations with fractions (Ministry of National Education [MONE], 2009a, 2009b).

With the aim of improving conceptual learning, students must be exposed to rich learning environments. The creation of such learning environments requires teachers to know the types of representation and the transitions between them. Mathematical 
knowledge that teachers and pre-service teachers should know also includes skills to relate mathematical operations to daily life situations (Ball et al. 2005). This requires teachers to have the skills to ensure transmissions between the written symbols and the real world (i.e., posing problems that could be solved using the following operation: $\frac{1}{2}+\frac{3}{4}=$ ? ).

Word problems on addition are classified as join (J) or part-part-whole (PPW) according to the semantic structure of the problem (Carpenter et al., 1996). Problems in the $J$ category involve a process as the initial amount, the change, and the resulting amount, while problems in the PPW category consist of the combination of two different parts that could be transformed into a whole (Van de Walle, 2004). For example, for the $\frac{1}{2}+\frac{1}{3}=$ ? operation, a problem such as I bought a pencil with ${ }^{\frac{1}{3}}$ of my money and a notebook with ${ }^{\frac{1}{2}}$ of it. How much have I spent?" would fall into the PPW category, as it involves the combination of the two have I spent?" would fall into the PPW category, as it

parts of a whole. The problem posed as "Ali walked ${ }^{\frac{1}{3}}$ kilometers. After resting for a while, he walked $\frac{1}{2}$ kilometers. How far did Ali walk in total?" would fall into the $\mathrm{J}$ category, as it contains an initial amount, a change amount, and a resulting amount.

NCTM (2000) calls for teachers to regularly ask students to pose problems based on a wide variety of situations. Crespo (2003) mentioned that problems posed by teachers presented opportunities to students for learning mathematics. Gonzales (1998) emphasized that including problem posing activities in lessons is dependent on the guidance of the teachers in posing accurate problems. Considering that contextual structures of problems display the different meanings attributed to operations (Carpenter et al., 1999) and problem posing is an assessment tool, analyzing the contextual structures of posed problems could provide information on the types of meanings attributed to the addition operation with fractions. In this respect, this study aimed to analyze problems posed by pre-service primary teachers on the addition operation with fractions according to their semantic structures. Additionally, the ways in which errors varied according to the semantic structures of the problems was also analyzed.

\section{METHOD}

\section{Sample}

One hundred sixty-two pre-service primary teachers participated in the study, with an age average of 21 and in their sixth semester of the program. Pre-service teachers took the Basic Mathematics I and II courses in the first and second semesters of the primary school teaching program of eight semesters. The aim of these courses is to improve the content knowledge of pre-service teachers regarding basic mathematical concepts. Additionally, Teaching Mathematics I and II are fifth and sixth semester programs. In these courses, the teaching methods of basic concepts related to numbers, measurement, geometry, and data learning are taught. Teaching of connection, representations, communication, reasoning, and problem solving (strategies and types of problems, etc...) are also included in the content of these courses. Pre-service teachers have received training in problem solving, types of problem posing, and methods of analysis. Each participant was assigned by the researcher certain codes such as PT1... PT162.

\section{Data Collection and Analysis}

The Problem Posing Test (PPT), used as a data collection tool, has four items. The first and second items involve operations on the addition of two proper fractions. The sum in the first item is a proper fraction, while the sum in the second item is a mixed fraction. The third item involves the addition of a proper fraction and a mixed fraction, while the fourth 
item involves the addition operation with two mixed fractions. Pre-service teachers were asked to pose two verbal problems related to daily life situations, which could only be solved using the given operation. Items of the test and their characteristics are presented in Table1.

Table 1. Items of PPT and their characteristics

$\begin{array}{ll}\text { Items } & \text { Characteristics } \\ \frac{1}{3}+\frac{1}{2}=? & \text { Addition of two proper fractions, where the sum is a proper fraction } \\ \frac{1}{2}+\frac{3}{4}=? & \text { Addition of two proper fractions, where the sum is a mixed fraction } \\ 2 \frac{1}{3}+\frac{2}{5}=? & \text { Addition of a proper fraction and a mixed fraction } \\ 2 \frac{1}{3}+3 \frac{1}{6}=? & \text { Addition of two mixed fractions }\end{array}$

Responses of pre-service teachers were analyzed in three stages. In the first stage, responses were classified as problem, not a problem, and blank. In this process, analysis schemes used by various researchers (Leung, 2013; Leung \& Silver, 1997; Silver \& Cai, 2005;) were utilized. Such an analysis aimed to determine the responses that could not be related to daily life situations and that did not have question roots. The category of "not $a$ problem" included responses where there was only description, there was one sentence or there were a few sentences, there were no question roots, or responses that could not be related to daily life situations.

In the second stage, responses in the category of problem were classified as $\mathrm{J}$ and PPW according to their semantic structures. In such a classification, the focus point is the classification of problems according to the story of the problem statement. Errors in the problems were not analyzed at this stage, where two problems posed for each item were classified as PPW/PPW, J/J and J/PPW. If one of the two responses to an operation was as problem and the other as not a problem or blank, then these types of responses were not included in the statistical comparative analysis.

Responses in the $\mathrm{J}$ and PPW categories were analyzed according to the types of errors they involved at the third stage. At this stage, data were analyzed through content analysis. Eight errors were determined in the problems posed by pre-service primary teachers. Next, the number of errors (there could be more than one type of error in a single problem) in responses in the form of PPW/PPW, J/J and J/PPW were calculated. Each type of error was given 1 point and the total error scores were calculated. For instance, if there were two and three errors respectively in two $\mathrm{J} / \mathrm{J}$ classified problems, the pre-service teacher was given 5 points for this problem-posing item. Therefore, a high score indicated a low level of problem posing performance. To determine whether there was difference between achievements of pre-service teachers of the PPW/PPW, J/J, and J/PPW categories in terms of problem posing, the Kruskal Wallis H-Test was administered. To determine the groups, between which the difference was observed, the Mann-Whitney U-test was used. Furthermore, the effect size was calculated for the groups, between which the difference was observed. The effect size indicates the difference between the mean rank of the two groups. According to Jacob Cohen's interpretation of the effect size (1998), anything greater than .5 is large, .5-.3 is moderate, .3-.1 is small, and anything smaller than .1 is trivial. The analysis scheme used in this study is displayed in Figure 1. Explanations regarding the stages in the analysis scheme and sample responses are presented in the results section.

Two different researchers analyzed problems posed by pre-service teachers to each item. Researchers were consistent with each other at percentages changing between $88 \%$ and $100 \%$. Next, the results of the analysis were compared and a consensus was arrived at for the categories, as well as the classification of error types. 


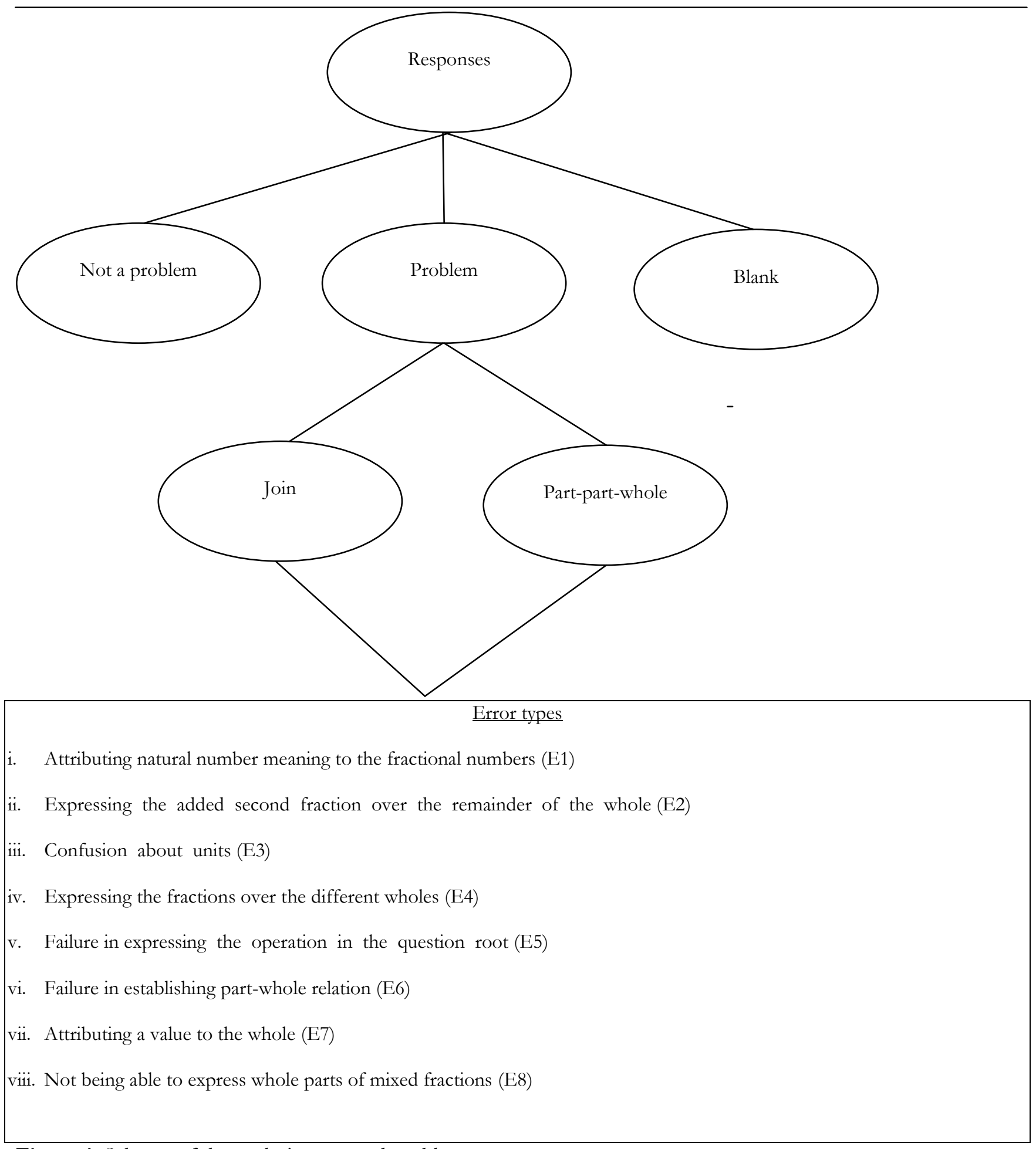

Figure 1. Scheme of the analysis on posed problems

\section{FINDINGS}

Findings related to the distribution of responses given by pre-service teachers

Distribution of responses given by 162 pre-service teachers to each problem posing items according to problem, not a problem, and blank categories is given in Table 2 . 
Table 2. Distribution of responses according to the problem, not a problem and blank categories

\begin{tabular}{cccccc} 
Items & \multicolumn{2}{c}{ Problem } & Not a problem & Blank & Total \\
& $\mathbf{P P W}$ & $\mathbf{J}$ & & & \\
Item 1 & $223(68.8)$ & $93(28.7)$ & $8(2.5)$ & $0(0)$ & $324(100)$ \\
Item 2 & $252(77.8)$ & $67(20.7)$ & $5(1.5)$ & $0(0)$ & $324(100)$ \\
Item 3 & $210(64.8)$ & $85(26.2)$ & $14(4.3)$ & $15(4.7)$ & $324(100)$ \\
Item 4 & $204(62.9)$ & $64(19.8)$ & $19(5.9)$ & $37(11.4)$ & $324(100)$ \\
Total & $889(68.6)$ & $309(23.8)$ & $46(3.5)$ & $52(4.1)$ & $1296(100)$ \\
\hline
\end{tabular}

*Data are presented in the form of frequencies (percentages).

According to Table 2, more than $80 \%$ of the responses to the items are in the problem category. The rate determined for the first and second items, in which the given fractions were proper fractions, was approximately $98 \%$. The rate drops to $80 \%$ for the third and fourth items. The percentage of responses listed under the not a problem category is $6 \%$. Pre-service teachers in this category gave responses without question roots or unrelated to daily life situations (i.e. A student walked ${ }^{\frac{1}{3}}$ of the distance. His friend walked half of the distance or what would be the sum if we add of $2 \frac{1}{3}$ of 30 and $\frac{2}{5}$ of 30?). Additionally, 68.6\% of the total 1296 responses is in the PPW category, whereas the remaining $23.8 \%$ is in the $\mathrm{J}$ category. Responses by some participants classified as PPW and $\mathrm{J}$ are as follows:

$$
2 \frac{1}{3} \text { of a whole box of tomatoes is red and } \frac{2}{5} \text { of the box is green. Find the total number of tomatoes }
$$
in the box (PT12).

Ahmet started the marble game with ${ }^{\frac{1}{2}}$ marbles. He won ${ }^{\frac{3}{4}}$ of the marbles in this game. How many marbles does he have at the end of the game? (PT55).

Responses by PT12 and PT55 contained question roots and they were related to daily life situations; therefore, they were classified in the problem category. The problem posed by PT12 involved the combination of two parts that could be transformed into a whole; therefore, it was classified as PPW. The problem that PT55 posed was classified as J as it sought the resulting amount by providing the initial amount and the change amount.

Findings related to the types of errors in the responses

Eight errors were determined in the problems posed by pre-service primary teachers. Explanations regarding the types of errors are as follows:

i. Attributing natural number meaning to the fractional numbers (E1): In this type of error, the participant attributed the natural number meaning to the addend or the result of the addition operation with fractions. The problem posed by PT17 is as follows: Mehmet has $\frac{1}{2}$ of the tennis balls. His friend gave him ${ }^{\frac{1}{3}}$ more balls. How many balls does Mehmet have? In the posed problem, tennis ball cannot be expressed through the $\frac{1}{2}$ fraction. Additionally, PT12 and PT55 used the following statements for fractions indicating the results of the addition operation with fractions: Find the total number of tomatoes in the box and how many marbles does he have at the end of the game? In fact, the number of tomatoes and marbles could be expressed in natural numbers instead of fractions.

ii. Expressing the added second fraction over the remainder of the whole (E2): In this type of error, pre-service teachers expressed the first fraction through a determined whole. The second addend fraction was expressed over the remainder of the whole. The problem posed by PT121 is as follows: Ece walked ${ }^{\frac{1}{3}}$ of the distance. After resting for a while she $\underline{1}$

walked $\overline{2}$ of the remaining distance. How far has Ece walked? The problem could be solved using the $\frac{1}{3}+\left(1-\frac{1}{3}\right) \times \frac{1}{2}$ operation. This solution to the problem does not match the given operation. 
iii. Confusion about units (E3): In this type of error, fractions were not expressed in appropriate units or the units written for the fractions did not match each other. The problem posed by PT71 was as follows: Ayse drank ${ }^{2 \frac{1}{3}}$ of a whole bottle of milk. Later, she drank $3 \frac{1}{6}$ liters of milk. How much milk did Ayse drink? The $2 \frac{1}{3}$ fraction represents the amount of milk drunk from a bottle of milk, while the $3 \frac{1}{6}$ fraction represents milk drunk in liters. Therefore, the fractions in the addition as $2 \frac{1}{3}$ and $3 \frac{1}{6}$ were not expressed using the same unit. On the other hand, the ${ }^{2 \frac{1}{3}}$ of a whole bottle of milk value represents an amount greater than the whole; therefore, it also has the E6 error.

iv. Expressing the fractions over the different wholes (E4): In this type of error, the fractions were expressed over different wholes. Unit fractions represented by the fraction numbers were different from each other and therefore, the addition could not be completed. $\frac{1}{2}$

The problem posed by PT113 was as follows: Elif gave $\frac{1}{2}$ of her money to Ayse and Cemre gave ${ }^{\frac{3}{4}}$ of her money to Ayse, too. How much money does Ayse have in total? In the problem statement, there was no mentioning that Elif and Cemre have the same amount of money.

$v$. Failure to express the operation in the question root (E5): This type of error contains responses that the verbal expressions indicating the addition operation do not correspond to the question root. The response by PT151 is as follows: I gave ${ }^{\frac{1}{3}}$ of my money to my elder brother, and ${ }^{\frac{1}{2}}$ of my money to my younger brother. How much of my money do I have now? The question root does not ask for the total amount of money given to the elder and younger brothers. It asks for the remaining amount of money.

vi. Failure in establishing part-whole relation (E6): This type of error contains responses that addend fractions or their addition is bigger than the whole. The problem posed by PT23 was as follows: Ali spent $\frac{1}{2}$ of his salary on shopping and ${ }^{\frac{3}{4}}$ of it for the bills. How much of his salary has he spent? When Ali spends $\frac{1}{2}$ of his salary, half of it will remain. Therefore, he cannot spend $\frac{3}{4}$ of his salary for the bills. Therefore, the problem statement is not meaningful in terms of part-whole relation.

vii. Attributing a value to the whole (E7): Pre-service teachers were asked to pose problems that could only be solved using the given operations. However, some pre-service teachers attributed numeric values to the whole and expressed that the fraction numbers were a certain amount of these numerical values. The problem posed by PT149 was as $\underline{1}$. $\frac{3}{4}$

follows: I have 24 nuts. Mehmet ate ${ }^{\overline{2}}$ of it and my friend ate $\overline{4}$ of it. How many nuts have my friend and I eaten? In addition to attributing a numeric value to the whole, there is E6 error in the problem statement.

viii. Not being able to express whole parts of mixed fractions (E8): This type of error involves the problems posed using the proper fraction numbers without taking the integer part of the fraction into consideration. PT12's response related to the $2 \frac{1}{3}+\frac{2}{5}=$ ? operation was as follows: Ayse drank ${ }^{\frac{1}{3}}$ of a bottle of milk. She gave $\frac{2}{5}$ of it to her cat. How much of the milk has she used?

Distribution of error types determined in problems posed by pre-service primary teachers according to the PPW and $\mathrm{J}$ categories are presented in Table 3. 
Table 3. Distribution of error types according to PPW and J categories

\begin{tabular}{ccccccccc}
\hline Errors & \multicolumn{2}{c}{ Item 1 } & \multicolumn{2}{c}{ Item 2} & \multicolumn{2}{c}{ Item 3 } & \multicolumn{2}{c}{ Item 4 } \\
& PPW & J & PPW & J & PPW & $J$ & PPW & J \\
E1 & $44(33.1)$ & $2(9.1)$ & $45(14.6)$ & $7(11.7)$ & $26(9.7)$ & $13(16.3)$ & $49(17.2)$ & $6(11.1)$ \\
E2 & $26(19.5)$ & $13(59.1)$ & $37(12)$ & $10(16.7)$ & $18(6.7)$ & $5(6.3)$ & $4(1.4)$ & $0(0)$ \\
E3 & $14(10.5)$ & $3(13.6)$ & $10(3.2)$ & $4(6.7)$ & $20(7.5)$ & $6(7.5)$ & $20(7)$ & $2(3.7)$ \\
E4 & $29(21.9)$ & $2(9.1)$ & $48(15.5)$ & $2(3.3)$ & $41(15.3)$ & $9(11.2)$ & $31(10.9)$ & $7(13)$ \\
E5 & $10(7.5)$ & $0(0)$ & $16(5.1)$ & $0(0)$ & $2(0.7)$ & $0(0)$ & $2(0.7)$ & $0(0)$ \\
E6 & $0(0)$ & $0(0)$ & $153(49.6)$ & $37(61.6)$ & $104(38.8)$ & $41(51.2)$ & $123(43.2)$ & $33(61.1)$ \\
E7 & $10(7.5)$ & $2(9.1)$ & $0(0)$ & $0(0)$ & $6(2.2)$ & $0(0)$ & $16(5.6)$ & $2(3.7)$ \\
E8 & $0(0)$ & $0(0)$ & $0(0)$ & $0(0)$ & $51(19.1)$ & $6(7.5)$ & $40(14)$ & $4(7.4)$ \\
Total & $133(100)$ & $22(100)$ & $309(100)$ & $60(100)$ & $268(100)$ & $80(100)$ & $285(100)$ & $54(100)$
\end{tabular}

Among the 316 problem statements posed for the first item of PPT, a total of 155 errors were determined and the average of errors was 0.49 . The error averages in this item under the PPW and $\mathrm{J}$ categories were 0.59 and 0.24, respectively. Among the 319 problem statements posed for the second item, a total of 369 errors were determined and the average of errors was 1.16. The error averages in this item under PPW and $\mathrm{J}$ categories were 1.23 and 0.89 respectively. Among the 295 problem statements posed for the third item, a total of 348 errors were determined. The average of errors in this item was 1.49 . The error averages in this item under the PPW and $\mathrm{J}$ categories were 1.28 and 0.94 , respectively. A total of 268 problem statements were posed for the final item and a total of 339 errors were determined. The error average for this item was 1.26. The error averages in this item under PPW and $\mathrm{J}$ categories were 1.39 and 0.84 , respectively. These findings show that depending on the increase in the number of mixed fractions in the operation, on which the problem is expected to be posed, the average of errors also increased. In addition, at all items of PPT, the average errors in the PPW category, were higher than that of the $\mathrm{J}$ category.

\section{Comparison of problem posing performance according to the semantic structures of problems}

Table 4 shows whether there were any differences in problem posing performances of pre-service teachers' responses in the PPW/PPW, J/J, and J/PPW categories. 
Table 4. Results of the Kruskal Wallis H-Test on differences between problem posing performances of preservice teachers according to the semantic structures of problems

\begin{tabular}{|c|c|c|c|c|c|c|}
\hline \multirow[t]{2}{*}{ Items } & Groups & $\mathbf{N}$ & Mean Rank & SD & $X^{2}$ & $\mathbf{P}$ \\
\hline & $\mathrm{PPW} / \mathrm{J}$ & 65 & 62.56 & & & \\
\hline \multirow[t]{3}{*}{ Item 1} & $\mathrm{~J} / \mathrm{J}$ & 14 & 70.04 & 2 & 22.55 & .000 \\
\hline & PPW/PPW & 79 & 95.11 & & & \\
\hline & $\mathrm{PPW} / \mathrm{J}$ & 43 & 53.01 & 2 & 27.58 & .000 \\
\hline \multirow[t]{3}{*}{ Item 2} & $\mathrm{~J} / \mathrm{J}$ & 12 & 70.71 & & & \\
\hline & PPW/PPW & 102 & 90.93 & & & \\
\hline & PPW/ J & 46 & 55.59 & 2 & 14.22 & .001 \\
\hline \multirow[t]{3}{*}{ Item 3} & $\mathrm{~J} / \mathrm{J}$ & 17 & 66.29 & & & \\
\hline & PPW/PPW & 79 & 81.89 & & & \\
\hline & PPW/ J & 32 & 36.91 & & & \\
\hline \multirow[t]{2}{*}{ Item 4} & $\mathrm{~J} / \mathrm{J}$ & 16 & 56.31 & 2 & 30.80 & .000 \\
\hline & $\mathrm{PPW} / \mathrm{PPW}$ & 78 & 75.88 & & & \\
\hline
\end{tabular}

* Significant at $\mathrm{p}<.05$

According to Table 4 there are statistically significant differences between groups in all items in terms of problem posing performance $(p<0.05)$. The Mann-Whitney U-test results indicate that the difference in the first item is only found between the $\mathrm{PPW} / \mathrm{J}$ and PPW/PPW categories $(U=1.496, z=-4.69, p=.000<0.05, r=-.39)$. On the other hand, no difference was observed between PPW/PPW and $\mathrm{J} / \mathrm{J}(U=390.50, p=.067>.05)$ or PPW $/ \mathrm{J}$ and $\mathrm{J} / \mathrm{J}\left({ }^{U=425.00}, p=.0625>.05\right)$ categories. The only difference in the second item was between the PPW $/ \mathrm{J}$ and PPW/PPW categories $(U=1134.00, z=-5.20$, $p=.000<.05, r=-.43$ ). However, no difference was found between PPW/PPW and $\mathrm{J} / \mathrm{J}$ $(U=454.000 ; p=.096>.05)$ categories or $\mathrm{PPW} / \mathrm{J}$ and $\mathrm{J} / \mathrm{J}(U=199.500 ; p=.178>.05)$ categories.

Similarly, the only difference in the third item was found between the PPW $/ \mathrm{J}$ and PPW / PPW categories $(U=1146.00, z=-3.71, p=.000<.05, r=.33$ ), whereas there was no difference between PPW $/$ PPW and $\mathrm{J} / \mathrm{J}(U=522.000, p=.117>.05)$ or PPW $/ \mathrm{J}$ and $\mathrm{J} / \mathrm{J}$ $(U=330.00, p=.314>.05)$ categories. In the fourth item, a difference was observed in all categories. Statistical results on these differences are as follows: PPW/J and PPW/PPW $(U=490.00, z=-5.27, p=.000<.05, r=-.51)$, PPW $/ \mathrm{J}$ and $\mathrm{J} / \mathrm{J}(U=163.00, z=-2.19$, $p=.028<.05, r=-.32)$, and PPW $/$ PPW and $\mathrm{J} / \mathrm{J}(U=416.00, z=-2.24, p=.025<.05$, $r=-.23)$. 


\section{CONCLUSIONS AND DISCUSSION}

Executing and algorithms or obtaining the correct answer do not imply conceptual understanding. If assessments only evoke procedural understanding, students' concepts are not explored (Graeber, 1999). Therefore, alternative assessment tools are used to determine students' conceptual understanding. Problem posing is considered an alternative evaluation tool in determining conceptual understanding skill, misconceptions, and errors. Ticha and Hošpesová (2009) stated that problem posing could be used as a diagnostic tool to discover the reasons for misconceptions and errors. Stoyanova (1998) emphasized a common agreement among researchers that problems posed by students gave important clues about their mathematical skills. Problem posing activities are also used in determining pre-service teachers' mathematical skills and knowledge (Kıliç, 2013).

A vast majority (92.4\%) of responses given by pre-service primary teachers were classified in the problem category. Sixty-eight point six percent of the responses in the problem category were listed under the PPW category. According to items, pre-service teachers made use of two different semantic structures (PPW and J) with 40\% (65 pre-service teachers) for the first item, while the percentage was below $28 \%$ for the other items. In other words, the percentages of pre-service teachers, who used two different semantic structures, were lower in situations, where at least one of the added fractions was a mixed fraction.

Eight errors were determined in the problems posed by pre-service primary teachers on addition operation with fractions. These types of errors have also been observed in other studies conducted with pre-service teachers in the literature (Issik et al., 2013; Issik \& Kar, 2012; Luo, 2009; McAllister \& Beaver, 2012; Toluk-Ucar, 2009). Therefore, these results indicate that errors in the transformation of symbolic expressions into verbal expressions have similarities at the international level. The most frequent error types made by preservice teachers in transforming symbolic expressions into verbal expressions are as follows: attributing natural number meaning to the fraction numbers, expressing the fractions over the different wholes and failure in establishing part-whole relation. These results are similar to the results of the study by McAllister \& Beaver (2012) on analyzing errors of preservice primary teachers in the problems posed on fraction operations. Charalambous et al. (2010) mentioned that difficulties experienced in fraction operations depended on the concept of fraction. The frequent errors observed in pre-service teachers at the conceptual level in this study are supportive of this conclusion.

In all items, for which the participants were expected to pose problems, the error averages in PPW type of problems were found to be higher than that of the $\mathrm{J}$ type. In this respect, performances of pre-service teachers in posing problems of the PPW type were lower than those of the $\mathrm{J}$ type. Considering the number of errors made, pre-service teachers, who were observed to pose PPW/J type of problems in all items, were found to be more successful than those who posed $\mathrm{J} / \mathrm{J}$ types of problems. Additionally, pre-service teachers, who posed $\mathrm{J} / \mathrm{J}$ type of problems, were found to be more successful than those posing PPW/PPW types of problems (Table 4). According to the statistical comparative analysis, differences were found between the problem posing performances of pre-service teachers, who responded at the PPW/J and PPW/PPW categories for the first three items. The effect size regarding this difference was determined to be at the medium level. However, at the fourth item the difference was observed at all groups statistically. In this item, the size of effect between PPW/J and PPW/PPW categories was determined to be large, while that of the PPW $/ \mathrm{J}$ and $\mathrm{J} / \mathrm{J}$ categories were determined to be small. Considering all items, pre-service teachers, who used two different semantic structures in the problems they posed, were found to perform statistically better than pre-service teachers in the PPW/PPW category.

This study concluded that, in general, problem-posing performances of pre-service teachers on addition operation with fractions were rather low. Additionally, problem-posing 
performances of pre-service teachers, who used two different semantic structures, were found to be better than those, who posed in monotype $(\mathrm{J} / \mathrm{J}$ and PPW/PPW) structures. This result indicates the importance of including problem posing activities with different semantic structures in teacher training programs. Analyses in this study were executed through four items prepared according to the addition operation with fractions. This could be seen as a limitation for the study. Similar studies could be conducted about operations, where natural numbers are added to proper fractions/mixed fractions. Results of such studies would contribute to the generalizations of the conclusions reached in this study. The number of pre-service teachers in certain groups was as low as 12 in the study (Table 4); this could be considered as another limitation. Therefore, similar studies could investigate wider sampling and present potential statistical differences between the groups clearly.

\section{REFERENCES}

Abu-Elwan, R. (2002). Effectiveness of problem posing strategies on prospective mathematics teachers' problem solving performance. Journal of Science and Mathematics Education, 25(1), 56-69.

Ball, D. L., Hill, H. H., \& Bass, H. (2005). Knowing mathematics for teaching: Who knows mathematics well enough to teach third grade, and how can we decide? American Educator, pp. 14-46.

Barlow, A. T., \& Cates, J. M. (2006). The impact of problem posing on elementary teachers' beliefs about mathematics and mathematics teaching. School Science and Mathematics, 106(2), 64-73.

Cai, J., \& Hwang, S. (2002). Generalized and generative thinking in US and Chinese students' mathematical problem solving and problem posing. Journal of Mathematical Behavior, 21, 401-421.

Carpenter, T. P., Fennema, E., \& Franke, M. L. (1996). Cognitively guided instruction: A knowledge base for reform in primary mathematics instruction. The Elementary School Journal, 97(1), 3-20.

Carpenter, T. P., Fennema, E., Franke, M. L., Levi, L., \& Empson, S. B. (1999). Children's mathematics: Cognitively guided instruction. Portsmouth, NH: Heinemann National Council of Teachers of Mathematics (2000). Principles and standards for school mathematics. Reston, VA: Author.

Charalambous, C. Y., Delaney, S., Hsu, H. Y., \& Mesa, V. (2010). A comparative analysis of the addition and subtraction of fractions in textbooks from three countries. Mathematical Thinking and Learning, 12, 117-151.

Christou, C., Mousoulides, N., Pittalis, M., PittaPantazi, D., \& Sriraman, B. (2005). An empirical taxonomy of problem posing processes. $Z D M, 37(3), 149-158$.
Cohen, J. (1988). Statistical power analysis for the behavioral science. New Jersey: Lawrence Erlbaum Associates, Inc., Publishers.

Contreras, J. (2007). Unraveling the mystery of the origin of mathematical problems: Using a problem-Posing framework with prospective mathematics teachers. The mathematics Educator, 17(2), 15-23.

Crespo, S. (2003). Learning to pose mathematical problems: Exploring changes in preservice teachers' practices. Educational Studies in Mathematics, 52, 243-270.

Dickerson, V. M. (1999). The impact of problemposing instruction on the mathematical problem-solving achievement of seventh graders (Unpublished doctoral dissertation). University of Emory, Atlanta.

English, L. D. (1998). Children's problem posing within formal and informal contexts. Journal for Research in Mathematics Education, 29(1), 83-106.

English, L. D. (2003). Problem posing in elementary curriculum. In F. Lester, \& R. Charles (Eds.), Teaching mathematics through problem solving. Reston, Virginia: National Council of Teachers of Mathematics.

Gonzales, N. A. (1998). A blueprint for problem posing. School Science and Mathematics, 94(2), 78- 85.

Graeber, A. O. (1999). Forms of knowing mathematics: what preservice teachers should learn. Educational Studies in Mathematics, 38, 189-208.

Iş1k, C. (2011). Conceptual analysis of multiplication and division in fractions posed by pre-service elementary mathematics teachers. Haccettepe University Journal of Education Faculty, 41, 231-243.

Iş1k, C., \& Kar, T. (2012). An error analysis in division problems in fractions posed by pre- 
service elementary mathematics teachers. Educational Sciences: Theory \& Practice, 12(3), 2289-2309.

Iş1k, C., Öcal, T., \& Kar, T. (2013). Analysis of pre-service elementary teachers' pedagogical content knowledge in the context of problem posing. Paper presented at the meeting of Eighth Congress of European Research in Mathematics Education (CERME 8), Antalya, Turkey.

K1lıç, Ç. (2013). Pre-service primary teachers' free problem-posing performances in the context of fractions: An example from Turkey. The Asia-Pacific Education Researcher, 1-10.

Lavy, I., \& Shriki, A. (2007). Problem posing as a means for developing mathematical knowledge of prospective teachers. Paper presented at the meeting of 31st Conference of the International Group for the Psychology of Mathematics Education, Seoul.

Leung, S. S. (2013). Teachers implementing mathematical problem posing in the classroom: challenges and strategies. Educational Studies in Mathematics, 1-14. doi: $10.1007 / \mathrm{s} 10649-012-9436-4$

Leung, S. S., \& Silver, E. A. (1997). The role of task format, mathematics knowledge, and creative thinking on the arithmetic problem posing of prospective elementary school teachers. Mathematics Education Research Journal, 9(1),5-24.

Luo, F. (2009). Evaluating the effectiveness and insights of pre-service elementary teachers' abilities to construct word problems for fraction multiplication. Journal of Mathematics Education, 2(1), 83-98.

McAllister, C. J., \& Beaver, C. (2012). Identification of error types in preservice teachers' attempts to create fraction story problems for specified operations. School Science and Mathematics 112(2), 88;98.

Ministry of National Education (MONE), (2009a). Elementary mathematics curriculum and manual: Grades 1-5, Ankara.

Ministry of National Education (MONE), (2009b). Elementary mathematics curriculum and manual: Grades 6-8, Ankara.

National Council of Teachers of Mathematics (NCTM). (2000). Principles and Standard for school mathematics. Reston, VA: National Council of Teachers of Mathematics.
Silver, E. A., \& Cai, J. (2005). Assessing students' mathematical problem posing. Teaching Children Mathematics, 12(3), 129135.

Silver, E. A. (1994). On mathematical problem posing. For the Learning of Mathematics, 14(1), 19-28.

Stoyanova, E. (1998). Problem posing in mathematics classrooms. In A. McIntosh, \& N. Ellerton (Eds.), Research in mathematics education: A contemporary perspective (pp.164-185). Perth: MASTEC Publication.

Stoyanova, E., \& Ellerton, N. F. (1996). A framework for research into students' problem posing. In P. Clarkson (Ed.), Technology in Mathematics Education (pp.518-525). Melbourne: Mathematics Education Research Group of Australasia.

Ticha, M., \& Hošpesová, A. (2009). Problem posing and development of pedagogical content knowledge in pre-service teacher training. Paper presented at the meeting of CERME 6, Lyon.

Toluk-Uçar, Z. (2009). Developing pre-service teachers understanding of fractions through problem posing. Teaching and Teacher Education, 25(1), 166-175.

Van de Walle, J. A. (2004). Elementary and midddle school mathematics (fifth edition). Virginia Commonwealth University press.

Yuan, X., \& Sriraman, B. (2010). An exploratory study of relationships between students' creativity and mathematical problem-posing abilities. In B.Sriraman, K. Lee (eds.), The Elements of Creativity and Giftedness in Mathematics.

\section{$\diamond \diamond \diamond$}

Citation Suggestions :

APA : Kar, T., \& Iş1k, C. (2014). Analysis of problems posed by pre-service primary teachers about adding fractions in terms of semantic structures. Mathematics Education, 9(2), 135-146. 